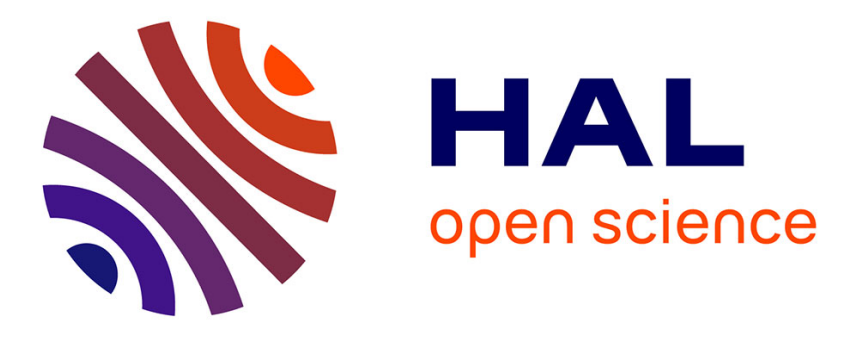

\title{
Thermal Runaway Robustness of SiC VJFETs
}

Rémy Ouaida, Cyril Buttay, Anh Dung Hoang, Raphaël Riva, Dominique

Bergogne, Hervé Morel, Christophe Raynaud, Florent Morel

\section{To cite this version:}

Rémy Ouaida, Cyril Buttay, Anh Dung Hoang, Raphaël Riva, Dominique Bergogne, et al.. Thermal Runaway Robustness of SiC VJFETs. Materials Science Forum, 2013, 740-742, pp.929-933. 10.4028/www.scientific.net/MSF.740-742.929 . hal-00799884

\section{HAL Id: hal-00799884 https://hal.science/hal-00799884}

Submitted on 12 Mar 2013

HAL is a multi-disciplinary open access archive for the deposit and dissemination of scientific research documents, whether they are published or not. The documents may come from teaching and research institutions in France or abroad, or from public or private research centers.
L'archive ouverte pluridisciplinaire HAL, est destinée au dépôt et à la diffusion de documents scientifiques de niveau recherche, publiés ou non, émanant des établissements d'enseignement et de recherche français ou étrangers, des laboratoires publics ou privés. 


\title{
Thermal Runaway Robustness of SiC VJFETs
}

\author{
R. Ouaida ${ }^{14 a}$, C. Buttay ${ }^{2 b}$ A. Hoang ${ }^{2}$, R. Riva ${ }^{2 c}$, D. Bergogne ${ }^{1 \mathrm{~d}}$, H. Morel $^{2 \mathrm{e}}$, \\ C. Raynaud ${ }^{2 f}$, F. Morel $^{3 \mathrm{~g}}$ \\ ${ }^{1}$ Université de Lyon, Université Lyon 1, lab. Ampère, CNRS UMR 5005, F-69622, France \\ ${ }^{2}$ Université de Lyon, INSA-Lyon, lab. Ampère, CNRS UMR 5005, F-69621, France \\ ${ }^{3}$ Université de Lyon, Ecole Centrale de Lyon, lab. Ampère, CNRS UMR 5005, F-69134, France \\ ${ }^{4}$ Thales Microelectronics, Thales group Cap Bretagne F-35370 Etrelles, France \\ aremy.ouaida@etu.univ-lyon1.fr, 'byril.buttay@insa-lyon.fr, rraphael.riva@insa-lyon.fr,

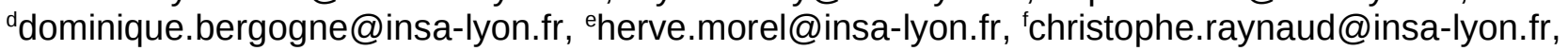 \\ gflorent.morel@ec-lyon.fr
}

Keywords: JFET, thermal runaway, high-temperature, power electronics

\begin{abstract}
Silicon Carbide (SiC) Junction-Field Effect Transistors (JFETs) are attractive devices for power electronics. Their high temperature capability should allow them to operate with a reduced cooling system. However, experiments described in this paper conclude to the existence of runaway conditions in which these transistors will reach destructive temperatures.
\end{abstract}

\section{Introduction}

One of the key advantage of SiC power devices over their Si counterparts is their ability to operate at higher temperature (in theory up to $1000^{\circ} \mathrm{C}$ for a $1000 \mathrm{~V}$-rated $\mathrm{SiC}$ device as compared to $200^{\circ} \mathrm{C}$ for a comparable Si device [1]). Practical tests have already demonstrated operation at elevated temperature. For example, in [2], SiC JFET and diode operate at $450^{\circ} \mathrm{C}$ ambient temperature, although with considerable de-rating in saturation current and blocking voltage.

The high-junction-temperature uses of power devices can be divided in two sets of applications: operation in harsh environment (aerospace, oil exploration...), and operation with reduced cooling (small heatsink, confined system...). An example of this latter application is given in [3], with a converter designed to operate at an ambient temperature of $150^{\circ} \mathrm{C}$ with a junction temperature of its power devices as high as $250^{\circ} \mathrm{C}$. This large drop between the junction and ambient temperatures allows for the use of a less sophisticated cooling system.

However, it has been demonstrated in [4] that the high temperature advantage of SiC might be limited because of thermal runaway issues. In a recent article [5], we studied this phenomenon on $\mathrm{SiC}$ diodes, and showed that purely unipolar diodes are prone to thermal runaway, whereas Merged PiN-Schottky (MPS) diodes are not.

A diagram explaining the thermal run-away mechanism is visible in fig 1: if we consider a simple cooling system (the plain line), it divides the Power/Temperature domain in two regions: in region A,

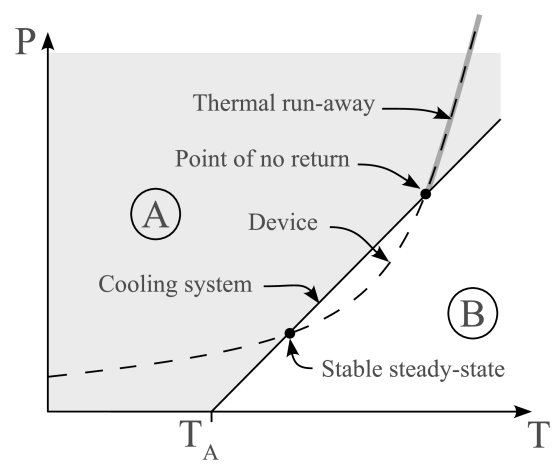

Fig 1: power dissipated by a device as a function of its temperature (dashed line), and cooling performance of its associated cooling system (plain) 
above the plain line, the power dissipated is higher than what the cooling system can extract. Any system in region A will then tend to heat-up. On the opposite, a system in region B would tend to cool down, as the power it dissipates is lower that what the cooling system can extract. If we assume the imaginary device plotted in figure 1 (dashed line), we can see that there are two equilibrium points, where the power dissipated by the device is equal to what the cooling system can extract. However, the topmost equilibrium point is unstable: in particular, a small increase in the device junction temperature puts it in region $\mathrm{A}$, where its temperature will increase indefinitely (that is, until the destruction of the device).

In this paper, we will investigate SiC JFET to find out if they are sensitive to such thermal runaway. We will first characterize some existing devices to build a model, and then use this model to simulate the thermal behaviour of the transistors.

\section{Experimental procedure}

In this paper, we performed I(V) measurements on two SiC JFETs. Both were manufactured by SiCED, but they correspond to two different generations of devices. The first has a $2.4 \times 2.4 \mathrm{~mm}^{2}$ die. The second, is more recent and was designed for higher power operation, with a $4.08 \times 4.08 \mathrm{~mm}^{2}$ die. Both have a $1200 \mathrm{~V}$ rating.

A special care was given to the test support to enable operation over a wide temperature range (- 70 to $300^{\circ} \mathrm{C}$, Fig 1). Several dies were mounted on custom-supports (a piece of ceramic substrate) using sintered silver [6]. A thick (350 $\mu \mathrm{m})$ copper leadframe was sintered to the substrate to provide convenient connections between the substrate and the test equipment. 4-point (Kelvin) connections to the source and drain were provided to minimize the influence of the support.

This support was connected to a Tektronix 371A high power curve tracer, operating in pulse mode to reduce the self-heating of the SiC JFET. The JFET was placed under the cap of a Thermonics T-2500E/300 temperature conditioner, to enable temperature forcing from -70 to $+300^{\circ} \mathrm{C}$, with $20^{\circ} \mathrm{C}$ increments. The temperature was measured on the backside of the substrate using a thermocouple.

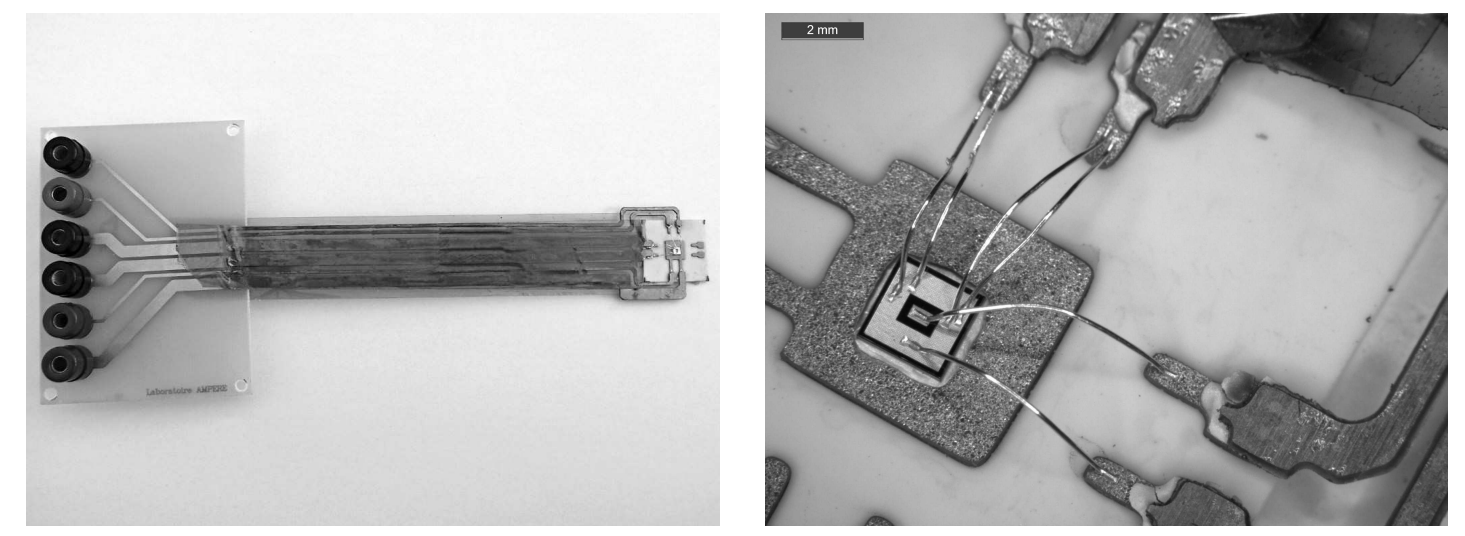

Fig 2: The test support, designed for high temperature operation (left) and a close-up picture of the $\mathrm{SiC}$ JFET die, with kelvin connections for more accurate forward characterization.

\section{Empirical Model}

Power electronics devices are designed be either fully off or fully on. For this analysis, we will only consider the "on" characteristic of the JFET. As the JFETs studied here are normally-on devices, this corresponds to a gate-to-source voltage $\left(\mathrm{V}_{\mathrm{gs}}\right)$ of $0 \mathrm{~V}$. Therefore, our analysis will focus on the losses and thermal stability of the JFETs in conduction mode only. A similar process can be applied to the blocking or switching losses, but it is beyond the scope of this paper.

A very simple, empirical model was fitted to the forward characteristic of the JFET:

$$
I_{D}=P_{0}(T)\left(1-e^{\left.-P_{1}(T) V_{D S}\right)}\right.
$$


Where $I_{D}$ is the drain current, $V_{D S}$ the drain-to-source voltage, $P_{0}$ and $P_{1}$ two empirical parameters which depends on the temperature $T$. This model was fitted successively with the data acquired for each temperature. This resulted in a set of $\mathrm{P}_{0}$ and $\mathrm{P}_{1}$ values, one for each temperature. This set was fitted to a second empirical equation:

$$
P_{0}=\alpha_{0} e^{\frac{-\left(T-\gamma_{0}\right)^{2}}{\delta_{0}}}+\sigma_{0}, P_{1}=\alpha_{1} e^{\frac{-\left(T-\gamma_{1}\right)^{2}}{\delta_{1}}}+\sigma_{1}
$$

Where $\alpha, \delta, \sigma$ and $\gamma$ are constants. Note that a simpler model could have been used, but the evolution of $\mathrm{P}_{0}$ and $\mathrm{P}_{1}$ with temperature was different between both JFET types. With eq (2), we were able to use the same identification procedure for the $2.4 \times 2.4$ and the $4 \times 4 \mathrm{~mm}^{2}$ JFETs.

The results of the identification procedure can be seen in figure 3 , where measurements and simulated results are superimposed.
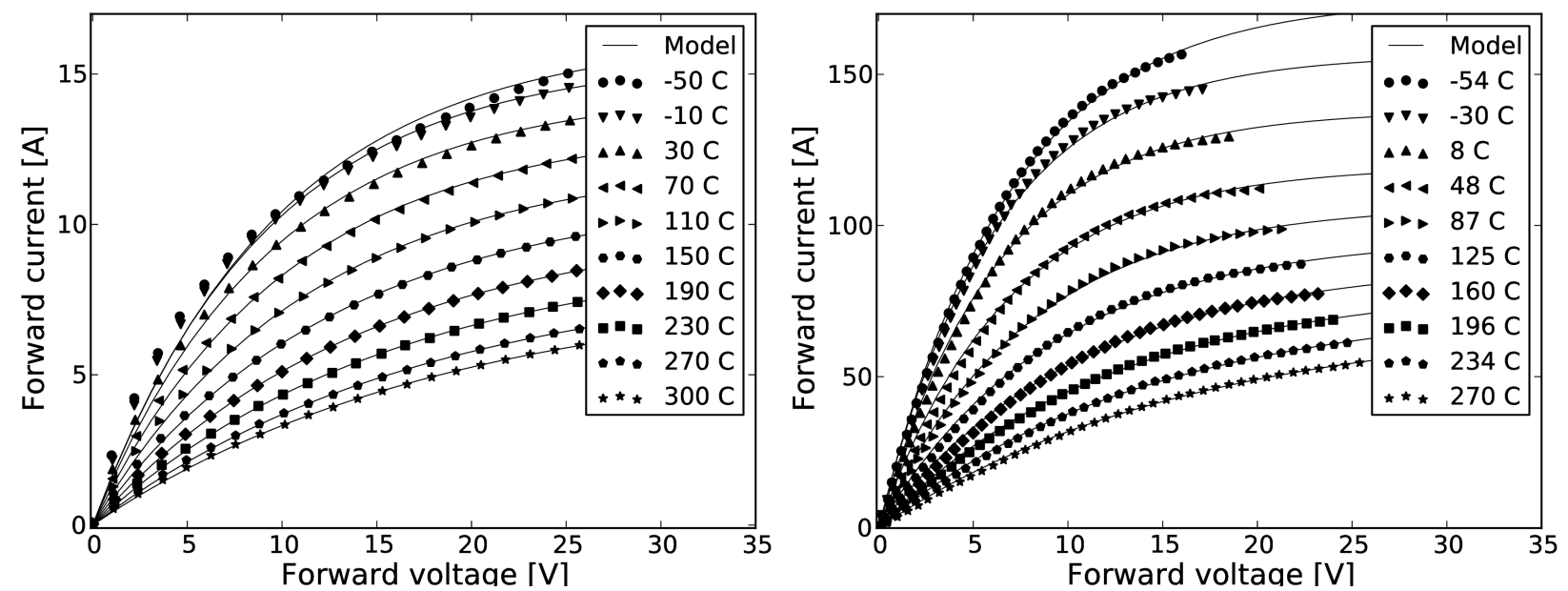

Fig 3: Forward characteristic of a fully-on JFET (i.e Vgs $=0 \mathrm{~V}$ ) as a function of the temperature for two JFETs: $2.4 \times 2.4 \mathrm{~mm}^{2}$ die size (left) and $4 \times 4 \mathrm{~mm}^{2}$ die size (right). Note that the vertical scales are different.

Table 1: Parameters of the JFET models

\begin{tabular}{cllllllll} 
device & $\alpha_{0}[\mathrm{~W}]$ & $\delta_{0}\left[{ }^{\circ} \mathrm{C}^{2}\right]$ & $\sigma_{0}[\mathrm{~W}]$ & $\gamma_{0}\left[{ }^{\circ} \mathrm{C}\right]$ & $\alpha_{1}[\mathrm{~W}]$ & $\delta_{1}\left[{ }^{\circ} \mathrm{C}^{2}\right]$ & $\sigma_{1}[\mathrm{~W}]$ & $\gamma_{1}\left[{ }^{\circ} \mathrm{C}\right]$ \\
\hline $2.4 \times 2.4 \mathrm{~mm}^{2}$ & 10.35 & 9422 & 6.61 & -130.7 & 0.0564 & 0.0510 & 0.0511 & -2.097 \\
\hline $4 \times 4 \mathrm{~mm}^{2}$ & $117.10^{3}$ & $932.10^{3}$ & 51.89 & -2588 & 0.0994 & 0.0604 & 0.0604 & -5.918 \\
\hline
\end{tabular}

\section{Thermal behaviour of the JFET}

Using this model, we were able to forecast the behaviour of the JFET over a slightly larger $\left(\mathrm{I}_{\mathrm{D}}, \mathrm{V}_{\mathrm{DS}}, \mathrm{T}\right)$ domain than used for the measurements. Fig 4 presents the power dissipated by both JFETs as a function of their drain current and junction temperature. As with fig. 1, we superimposed the characteristic of some cooling systems (thick lines), operating in $25^{\circ} \mathrm{C}$ ambient, with thermal resistances of 1, 2, 4 and $8 \mathrm{~K} / \mathrm{W} .1 \mathrm{~K} / \mathrm{W}$ corresponds to a very efficient cooling system, while $8 \mathrm{~K} / \mathrm{W}$ is much easier to achieve.

\section{Discussion and Conclusion}

As a result, it appears that the thermal runaway phenomenon can be observed (for example, the "6 A" characteristic of the $2.4 \times 2.4 \mathrm{~mm}^{2} \mathrm{JFET}$ and the "2 K/W" cooling system in figure 4 look very similar to the example in figure 1). Furthermore, the upward bend exhibited by the devices characteristic in figure 4 is more pronounced than expected in theory [4]. In [4], the increase in dissipated power with temperature is associated with the increase in electrical resistivity of the drift layer. For the JFET studied here, the increase in dissipated power (i.e. in voltage drop) is not only 
caused by this increase in resistivity, but also by the decrease in the saturation current with the temperature.
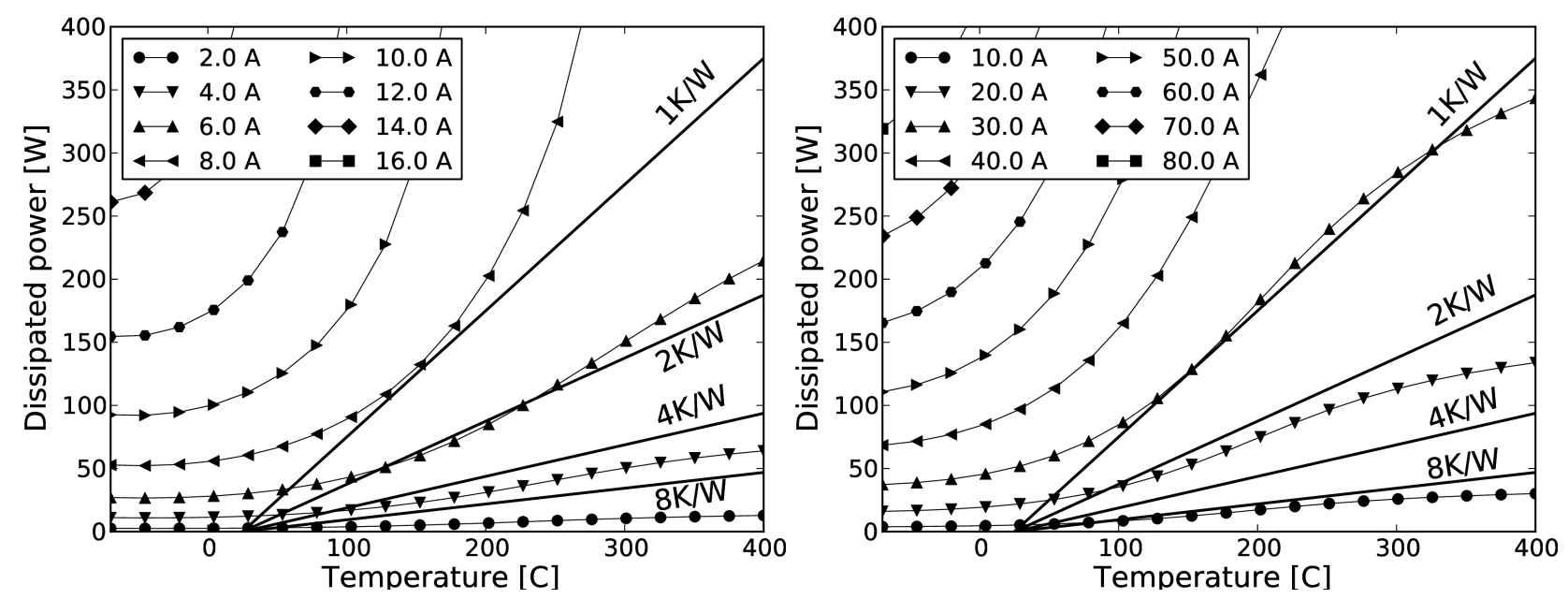

Fig 4: Dissipated power as a function of the forward current for a $2.4 \times 2.4$ (left) and a $4 \times 4 \mathrm{~mm}^{2}$ (right) JFET. Note that the forward current values are different between graphs

Although able to operate at high junction temperature, SiC JFETs are not insensitive to the thermal runaway mechanism. This means that even in a mild ambient temperature, they should be provided with a proper cooling system. This is especially important in the case of system that can be submitted to transient current or temperature overloads. For example, in the case of a $2.4 \times 2.4 \mathrm{~mm}^{2}$ JFET (Fig 4., left) operating with $\mathrm{I}_{\mathrm{D}}=6 \mathrm{~A}$ and a $2 \mathrm{~K} / \mathrm{W}$ cooling system in a $25^{\circ} \mathrm{C}$ ambient, any increase in the ambient temperature (i.e any shift of the cooling characteristics towards the right) will trigger the thermal runaway. It would be much safer to limit this transistor to 2 or $4 \mathrm{~A}$.

Another interesting information from fig.4 (right) is the downward bend exhibited (for example) by the 30 A characteristic. This means that it should be possible to design the transistors to minimize their sensitivity to thermal runaway.

\section{Acknowledgement}

The authors thank Thales microelectronics for the wirebonding of the test vehicles, and the Fondation de Recherche pour l'Aéronautique et l'Espace (FRAE) for their financial support under the grant EPAHT.

\section{References}

[1] Raynaud, C. et al. "Comparison of high voltage and high temperature performances of wide bandgap semiconductors for vertical power devices" Diamond and Rel. Materials, 2010, 19, p.1 -6

[2] Funaki, T. et al. "Power Conversion With SiC Devices at Extremely High Ambient Temperatures" IEEE Tr Power Elec., 2007, 22, p 1321-1329

[3] Hornberger, J. M. et al. "A High-Temperature Multichip Power Module (MCPM) Inverter utilizing Silicon Carbide (SiC) and Silicon on Insulator (SOI) Electronics" Proc. PESC Conf., IEEE, 2006, p 9-15

[4] Sheng, K. "Maximum Junction Temperatures of SiC Power Devices" IEEE Tr. Elec; Dev., 2009, 56, p 337-342

[5] Buttay, C. et al. "Thermal Stability of Silicon Carbide Power Diodes" IEEE tr. Elec. Dev., 2012, 59, p. 761-769

[6] Masson, A.et al.."High-temperature die-attaches for SiC power devices“ Proc. 2011-14th European Conf. Power Electronics and Applications (EPE 2011), 2011, 1-10 